\title{
Pyrolytic behavior of lignocellulosic-based polysaccharides
}

\author{
Maryam Ghalibaf ${ }^{1} \cdot$ Tharaka Rama Krishna C. Doddapaneni $^{2} \cdot$ Raimo Alén $^{1}$
}

Received: 10 July 2018/Accepted: 11 November 2018/Published online: 23 November 2018

(C) The Author(s) 2018

\begin{abstract}
The thermochemical behavior of cellulose, glucomannan, and xylan was investigated by pyrolysis-gas chromatographymass spectrometry (Py-GC/MS). In each case, major GC-amenable condensable products were classified into several compound groups, and the formation of these monomer-related fragments from the model substance samples was determined at 500, 600, and $700{ }^{\circ} \mathrm{C}$ with a residence time of $5 \mathrm{~s}$ and $20 \mathrm{~s}$. The results revealed that despite some general formation trends, no compound group was selectively formed at certain temperatures. Of the 11 product groups, the primary ones, including lactone, furan, and cyclopentenone derivatives, accounted for 72-85\% (from cellulose), 86-90\% (from glucomannan), and $76-81 \%$ (from xylan) of the total amount of pyrolysis products determined. At $500{ }^{\circ} \mathrm{C}$, about half of the major product groups accounted for lactones, such as 3-hydroxy-2-penteno-1,5-lactone and $5 \mathrm{H}$-furan-2-one. It was also confirmed by thermogravimetric analyses that within the temperature range studied, cellulose was thermally more stable than the heterogeneous hemicelluloses. These kinds of data are of importance, for example, with respect to efforts to develop new biorefinery possibilities for renewable resources.
\end{abstract}

Keywords Cellulose $\cdot$ Glucomannan $\cdot$ Xylan $\cdot$ Pyrolysis-gas chromatography $\cdot$ Condensable products $\cdot$ Thermogravimetry

\section{Introduction}

The biorefinery concept can be defined merely as a process for fractionating and/or converting into energy carbon dioxide-neutral feedstock (biomass) as well as a great variety of chemicals and other biomaterials in an ecosystem-friendly way through advanced technologies [1,2]. The pulp industry, as an essential branch of global industry, is based on vast and multidisciplinary technology. For example, a modern chemical pulp mill that employs one fibrous feedstock is capable of manufacturing, besides pulp, several pulping by-products, and it can be considered a rather sophisticated biorefinery. It is also known that the

Electronic supplementary material The online version of this article (https://doi.org/10.1007/s10973-018-7919-y) contains supplementary material, which is available to authorized users.

Maryam Ghalibaf

maryam.m.ghalibaf@jyu.fi

1 Laboratory of Applied Chemistry, University of Jyväskylä, P.O. Box 35, 40014 Jyväskylä, Finland

2 Laboratory of Chemistry and Bioengineering, Tampere University of Technology, P.O. Box 541, 33101 Tampere, Finland integration of a hot-water-extraction pre-treatment stage prior to alkaline pulping may offer a feasible possibility, mainly to recover the dissolved carbohydrates-derived material for further utilization by biochemical and chemical technologies [3]. This concept of an integrated forest biorefinery has been investigated under a variety of conditions and from several points of view.

In our earlier papers, we used pyrolysis-gas chromatography/mass spectrometry (Py-GC/MS) for revealing the thermochemical behavior of silver birch [4] and Norway spruce [5] sawdust, as well as non-wood materials, such as okra and miscanthus [6]. In all cases, the effects of pyrolysis conditions on the product distribution were studied. All the materials were investigated as such and after hot-water extraction together with the pulps obtained from these feedstocks by sulfur-free delignification. In each case, major GC-amenable condensable products were determined and classified into several compound groups, characteristically originated from the main structural constituents (cellulose, hemicelluloses, and lignin) of the raw materials. Additionally, the suitability of this analytical pyrolysis method under varying conditions was investigated as a rapid tool for roughly detecting chemical changes that were taking place in the feedstocks during the different treatments performed. 
Thermal analysis can be defined as a set of techniques used to describe the physical or chemical changes associated with substances as a function of temperature [7]. The thermal behavior of lignocellulosic materials and their components can be studied in many alternative ways. PyGC/MS reveals the composition of products and indicates the mechanisms of degradation reactions; it also provides information about the original structure of the samples being studied. In general, many studies indicated that during pyrolysis under an inert atmosphere, biomass converts into low-degree-polymerized products [8-17]. However, there have still been less attention on pyrolysis of glucomannan and xylan as well as their quantification analyses. The dissimilarities in pyrolysis behavior of the main components in lignocellulosic biomass are due to differences in their molecular structures and chemical natures. Therefore, the study of pyrolysis behavior of the main biomass substituents is essential to understand the overall pyrolysis behavior of biomass. In contrast, thermal gravimetric (TG) analysis (i.e., mass change vs. temperature) and differential scanning calorimetry (DSC) (i.e., heat flux vs. temperature) primarily give information concerning the mass loss of a sample over the whole process, the rate of mass loss, and the endothermic and exothermic temperature ranges upon heating. These methods are widely applied techniques, especially for the study of thermal stability of polymers. In practice, it is useful to record the first derivative of the TG curve (i.e., differential thermogravimetry (DTG)) for more clearly detecting small features/boulders as peaks on the curve. Particularly, successful approaches have also been the simultaneous combination of TG methods and spectroscopic techniques. In general, the mass loss of a sample of the TG curve under a certain heating rate and the peak height of the DTG curve are directly related to the temperature during the process and the reaction rate at the corresponding temperature, respectively. Therefore, investigation of samples by TG and DTG is also important due to fluctuations in available data [18-21].

The cellulose content is $40-45 \%$ of the wood dry solids and this carbohydrate is a linear homopolysaccharide composed of $\beta$-D-glucopyranose moieties linked together by $(1 \rightarrow 4$ )-glycosidic bonds (degree of polymerization (DP) $10,000-15,000)$ [22]. Many degradation mechanisms with varying reaction kinetics of cellulose pyrolysis have been proposed under changing conditions [23-32]. In the generally accepted pyrolysis reactions on heating after gradual depolymerization, mainly by breaking of glycosidic linkages, a great variety of volatile products are simultaneously formed (the prominent primary example is levoglucosan (LG)). This occurs from the initial degradation reactions, including dehydration, rearrangement, and ring-opening of glucose units, followed by the formation of various unsaturated products from which a highly reactive char can be obtained by condensation.

Hemicelluloses $(25-35 \%$ of the wood dry solids) are linear low-molar-mass heteropolysaccharides with specific side-groups, and their thermal and chemical stability is generally lower than that of cellulose, presumably due to their lack of crystallinity and lower DP (100-200) [33, 34]. Softwoods and hardwoods (and non-woods) differ not only in the content of total hemicelluloses but also in the percentages of individual hemicellulose constituents; in hardwoods and non-woods, primarily xylan (containing xylose units), and in softwoods, mainly glucomannan (containing mannose and glucose units). In hardwoods, the content of xylan and glucomannan is $20-30 \%$ and $<5 \%$ of the wood dry solids, respectively, whereas in softwoods, the corresponding contents are $5-10 \%$ and $15-20 \%$ of the dry wood solids [33]. The thermal degradation reactions of heteropolymeric hemicelluloses are principally similar to those of homopolymeric cellulose, although hemicelluloses reacted more readily than cellulose during heating $[13,18,34-36]$. The differences observed in the degradation rates of various polysaccharides can be explained as being primarily due to the different glycosidic bonds between sugar moieties as well as different DP and crystallinity of cellulose. Of the hemicelluloses, xylan is the least thermally stable because it is more susceptible than glucomannan to degradation of glycosidic bonds and dehydration reactions [37]. In general, the char formation from hemicellulose pyrolysis is slightly higher than that from cellulose [13, 14, 19, 38].

Lignin is an amorphous polymer with a chemical structure that distinctly differs from the polysaccharide constituents of wood and non-wood biomass [33, 39]. It is generally known that lignin decomposes over a wider temperature range compared to cellulose and hemicelluloses, which are less resistant to thermal degradation and rapidly degrade at lower temperatures over narrower temperature ranges $[19,37,40]$. Thus, the stability of lignin, cellulose, and hemicelluloses against heating increases in the order: hemicelluloses $>$ cellulose $>$ lignin.

A wide range of studies has been made for clarifying the pyrolysis characteristics of varying biomasses by different analytical and pilot-scale techniques [11, 40-46]. Typically, it has been assumed that the pyrolysis behavior of biomass is almost the integration of its components (cellulose, hemicelluloses, and lignin) [13, 23], although the cellulosic contribution normally predominates due to the larger proportion of cellulose in lignocellulosic materials. Hence, it can be observed that with the increasing amount of hemicelluloses in the sample mixture of xylan and microcrystalline cellulose, the maximum decomposition rate of hemicelluloses increases while that for cellulose declines [13]. Unlike the cellulose, the interaction between 
hemicelluloses and lignin is strong. The presence of hemicelluloses decreases the lignin decomposition temperature and the mass loss rate, whereas the existence of lignin increases the decomposition rate of hemicelluloses.

In our earlier studies, we investigated the thermochemical behavior of differently treated wood and non-wood materials [4-6]. In this comparable study with model substances, firstly, the aim was to further clarify the formation of compound groups under the same pyrolysis conditions as those applied in our previous experiments. Secondly, to verify the formation of main pyrolysis products with respect to their main carbohydrate constituents as well as the effect of the interaction of main carbohydrate constituents in hardwood, softwood, and non-wood on the pyrolysis products. Since carbohydrates are the main components of various biorefinery fractions, we selected for our Py-GC and TG experiments cellulose and hemicelluloses (glucomannan and xylan) and the quantification analyses of GC-detectable pyrolysis products of these samples were reported. The thermochemical behavior of lignin as well as lignin-containing black liquors from alkaline delignification of wood and non-wood fibrous feedstocks will be separately investigated under the analogous conditions in the forthcoming studies.

\section{Experimental}

\section{Thermogravimetric analyses}

The slow pyrolysis of the selected biomass components was carried out with a Linseis STA PT1600 instrument. For each test, a sample size of 10-15 mg was used in an alumina crucible. A nitrogen flow of $200 \mathrm{~mL} \mathrm{~min}{ }^{-1}$ was used to create inert environment and to remove the released volatiles. For drying, the furnace temperature was raised from room temperature $\left(\approx 20{ }^{\circ} \mathrm{C}\right)$ to $105^{\circ} \mathrm{C}$ at $20{ }^{\circ} \mathrm{C}$ $\min ^{-1}$ and maintained at that temperature for $30 \mathrm{~min}$ to complete the drying of the sample. Then, the TG run was continued with the same dried samples for pyrolysis. The pyrolysis temperature was selected as $700{ }^{\circ} \mathrm{C}$. For pyrolysis, the sample temperature was raised from $105^{\circ} \mathrm{C}$ to $700{ }^{\circ} \mathrm{C}$ at varied heating rates of 10,15 , and $20{ }^{\circ} \mathrm{C} \mathrm{min}{ }^{-1}$ and maintained at that temperature for $40 \mathrm{~min}$ to ensure complete pyrolysis. The data generated through TG experiments were further processed with Microsoft Excel and MATLAB ${ }^{\circledR}$.

\section{Pyrolysis experiments}

The model substances were $\alpha$-cellulose (Sigma), glucomannan (MB Med. S. r. L.), and oat spelt xylan (Sigma). In each case, about $0.2 \mathrm{mg}$ of model substances was pyrolyzed in a quartz tube $(3.0 \mathrm{~cm} \times 1.0 \mathrm{~mm}$ inner diameter) between quartz wool which was used to keep the solids inside the pyrolysis tube. First, a partly filled quartz tube with quartz wool was cleaned at $1000{ }^{\circ} \mathrm{C}$ to remove all adsorbed gases and vapors on the surface of the quartz tube. Then, fast pyrolysis of substances was conducted at a temperature of 500,600 , or $700{ }^{\circ} \mathrm{C}$ (heating rate $20{ }^{\circ} \mathrm{C}$ $\mathrm{ms}^{-1}$ and heating times 5 and $20 \mathrm{~s}$ ) using a CDS Pyroprobe 1000 heated filament pyrolyzer coupled to an HP 5890 II gas chromatograph (Py-GC, Hewlett Packard Company, Wilmington, NC, USA).

The GC conditions were the same as those applied earlier to the similar purpose [4]. The column was a ZB-35HT (Inferno) capillary GC column $(30 \mathrm{~m} \times 0.25 \mathrm{~mm}$ with a film thickness of $0.25 \mu \mathrm{m}$ ). The $\mathrm{GC}$ oven temperature program in the analyses of pyrolysis products was as follows: 2 min at $40{ }^{\circ} \mathrm{C}, 4{ }^{\circ} \mathrm{C} \mathrm{min}^{-1}$ to $190{ }^{\circ} \mathrm{C}, 10{ }^{\circ} \mathrm{C} \mathrm{min}{ }^{-1}$ to $320{ }^{\circ} \mathrm{C}$, and $10 \mathrm{~min}$ at $320^{\circ} \mathrm{C}$. Helium was used as the carrier gas with a gas flow rate of $1 \mathrm{~mL} \mathrm{~min}{ }^{-1}$ and as an inert atmosphere in the pyrolysis interface. Detection was carried out with an HP 5970 mass spectrometric detector under electron ionization $(70 \mathrm{eV})$ with 2.92 scan per seconds in the $30-550 \mathrm{~m} / \mathrm{z}$ interval.

Compounds were identified using the National Institute of Standards and Technology (NIST) mass spectral library. Quantitative analysis was conducted according to our previous study with a set of standard samples of known concentration based on duplicated injections [4]. To utilize this, standard solutions for the low concentration range of $0.05-1.0 \mathrm{mg} \mathrm{mL}^{-1}$ and for the high concentration range of $1.0-8.0 \mathrm{mg} \mathrm{mL}^{-1}$ were prepared, depending on the standard's chromatographic response (GC/MS). The conditions of the GC were set to those of the Py-GC/MS. To obtain the yields of GC-detectable products, a plot of instrument response (i.e., peak area, y-axis) versus amount of standard solution ( $\mu \mathrm{g}, x$-axis) was performed. Therefore, the relative mass response of a target compound compared to the mass of the corresponding external standard was extracted from plot and the corresponding yield (supplementary S1-3) was calculated based on the initial sample. In addition, the quantification analyses are given in the supplementary data (S4).

Elemental analysis was performed with a CHNOS elemental analyzer GmbH (Vario EL III) to identify the content of carbon, hydrogen, nitrogen, and oxygen (Table 1). The tests were conducted in duplicates. 
Table 1 Elemental analysis of cellulose, glucomannan, and xylan. Numbers in parentheses are calculated for "pure substances" without any possible side-groups

\begin{tabular}{lllll}
\hline Component & $\mathrm{C}$ & $\mathrm{H}$ & $\mathrm{N}$ & $\mathrm{O}^{\mathrm{a}}$ \\
\hline Cellulose & $43.25(44.45)$ & $6.32(6.21)$ & $-(-)$ & $50.43(49.34)$ \\
Glucomannan & $39.96(44.45)$ & $6.35(6.21)$ & $0.28(-)$ & $53.41(49.34)$ \\
Xylan & $41.57(45.46)$ & $6.47(6.11)$ & $-(-)$ & $51.96(48.43)$ \\
\hline
\end{tabular}

${ }^{\mathrm{a} C}$ Calculated by difference

\section{Results and discussion}

\section{Thermogravimetric considerations}

The temperature at which decomposition reactions of wood occur and the changes in specimen mass associated with the reactions can be found by thermogravimetric analysis, which exactly recorded the mass loss of the solid sample versus temperature/time. Traditionally, the chemical kinetic models for the biomass and its components are proposed from the analysis of the different mass loss stages and validated through the correlation between the predicted data and the experimental mass loss curve. According to TG the mass loss of cellulose and hemicelluloses typically starts at about $100{ }^{\circ} \mathrm{C}$ (i.e., due to the loss of adsorbed water). At temperatures between 100 and $250{ }^{\circ} \mathrm{C}$, the rate of mass loss is quite slow, but above $250{ }^{\circ} \mathrm{C}$, it increases [19]. For example, cellulose undergoes an extensive endothermic-exothermic sequence immediately above $300{ }^{\circ} \mathrm{C}[20,47]$, and it has been reported that for xylan, displaying clear exothermic behavior [48], the most intensive thermal degradation takes place in the temperature range $200-260{ }^{\circ} \mathrm{C}[19,49]$.

Figure 1 shows TG and DTG curves of cellulose, glucomannan, and xylan. The average active pyrolysis ranges of $290-410{ }^{\circ} \mathrm{C}$ and $230-340{ }^{\circ} \mathrm{C}$ were observed for

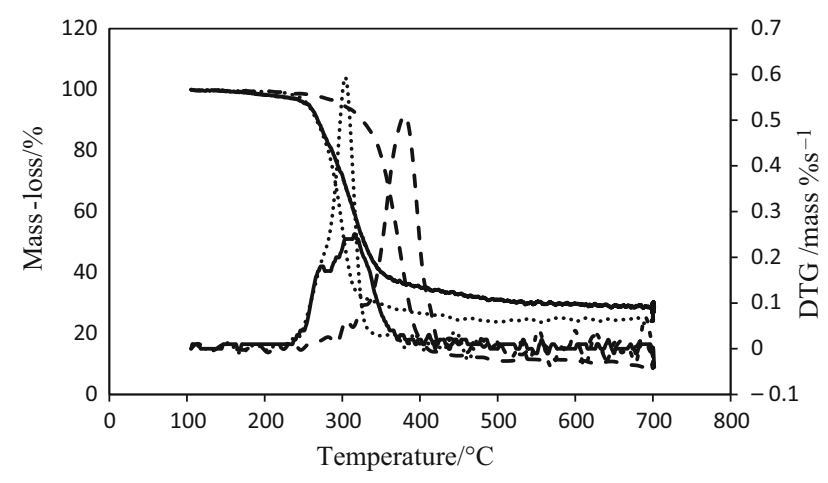

- - - Cellulose Glucomannan ......... Xylan

Fig. 1 TG and DTG curves of cellulose, glucomannan, and xylan at $20{ }^{\circ} \mathrm{C} \min ^{-1}$ cellulose and hemicelluloses, respectively. The higher thermal stability of cellulose (glucan-based polysaccharide), compared to amorphous hemicelluloses with several types of glycosidic bonds and side-groups, was mainly attributed to its unbranched and ordered (i.e., highly crystalline) structure $[1,19,21,41,50]$. Among the hemicelluloses, xylan had lower thermal stability than glucomannan. The pyrolysis char yield determined was 9 , 27 , and $25 \%$ of the initial mass for cellulose, glucomannan, and xylan, respectively. This finding agreed well with the earlier data $[19,51]$ and suggested more multiple reactions of heterogeneous hemicelluloses and their monosaccharide moieties. According to [51], the differences in the char yield between cellulose and hemicelluloses are clearly due to the somewhat different pyrolysis reaction mechanisms. The DTG peak heights (wt $\% \mathrm{~s}^{-1}$ ) were as follows: cellulose 0.48 at $382{ }^{\circ} \mathrm{C}$, glucomannan 0.25 at $316^{\circ} \mathrm{C}$, and xylan 0.57 at $304{ }^{\circ} \mathrm{C}$.

The calculated, based on the Flynn-Wall-Ozawa method [52] activation energy $\left(E_{a}\right)$, value as a function of fractional conversion $(\alpha)$ for cellulose, glucomannan, and xylan is presented in Fig. 2. It could be noted that the variation in $E_{a}$ was slightly lower for cellulose (142-162 $\mathrm{kJ} \mathrm{mol}^{-1}$ ) than for glucomannan and xylan. In the literature, depending on the sample origin, a variety of $E_{a}$ values for cellulose have been given; for example, an average value of $109.4 \mathrm{~kJ} \mathrm{~mol}^{-1}$ [50]. The $\mathrm{E}_{\mathrm{a}}$ value for glucomannan varied between 111 and $301 \mathrm{~kJ} \mathrm{~mol}^{-1}$, and it gradually increased in the progress of pyrolysis. However, at the end of pyrolysis $(\alpha>0.7)$, a rapid rise (i.e., from 160 to $300 \mathrm{~kJ} \mathrm{~mol}^{-1}$ ) was observed. This phenomenon has also been reported earlier by [53]. They also reported the $E_{a}$ values between 181 and $206 \mathrm{~kJ} \mathrm{~mol}^{-1}$ for glucomannan in the $\alpha$ range $0.1-0.75$. In the case of xylan, the $E_{\text {a }}$ value $\left(168-200 \mathrm{~kJ} \mathrm{~mol}^{-1}\right)$ increased until $\alpha=0.6$, and, after this point, it started to decrease. In the previous study [54], the $E_{\mathrm{a}}$ values for xylan were between 150 and $250 \mathrm{~kJ} \mathrm{~mol}^{-1}$ in the temperature range $185-215{ }^{\circ} \mathrm{C}$.

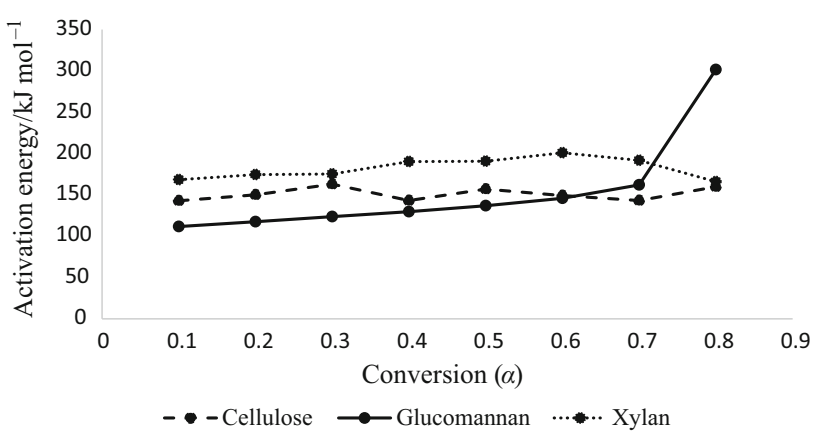

Fig. 2 Activation energy $\left(E_{\mathrm{a}}\right)$ as a function of fractional conversion $(\alpha)$ for cellulose, glucomannan, and xylan 
It has been reported [55] that the significant variation in the $E_{\mathrm{a}}$ value with respect to $\alpha$ indicates a multi-step reaction mechanism. Practically, the present data suggested that cellulose degradation during pyrolysis proceeded via reasonably simple and straightforward mechanisms without any significant secondary reactions. In contrast, it could be concluded that, due to greater variation in the $E_{\mathrm{a}}$ values for hemicelluloses, their degradation during pyrolysis took place by somewhat more complicated reaction mechanisms as already indicated by the high-char yields. The thermal degradation of the polysaccharides studied occurred by versatile parallel reaction paths that were not characteristically specific for certain temperature ranges. Hence, with this respect, TG, without any definite detention possibilities, could not suggest distinct differences in their thermochemical degradation behavior.

\section{Pyrolysis: gas chromatographic analyses}

The integrated chromatographic system GC/MS applied resolved most of the low-molar-mass compounds released from the model substances during pyrolysis; altogether, 42 from cellulose, 47 from glucomannan, and 41 from xylan were identified in conformity with pure compounds and MS library. For simplicity, the dominant GC-amenable pyrolysis products were classified into illustrative compound groups by the same system as that used earlier for similar purposes $[4,5]$. It could be roughly concluded that the groups of anhydrosugar (A), cyclopentenone $(C)$, furan $(\mathrm{F})$, indene $(\mathrm{I})$, lactone $(\mathrm{L})$, and pyrone $(\mathrm{Y})$ derivatives originated from carbohydrates, and those of guaiacol (G) and phenol (P) derivatives originated from lignin. The characteristic groups of naphthalene $(\mathrm{N})$ derivatives were obtained from extractives, whereas the groups of other aromatics, benzene (B) and linear ketones (LK) derivatives, were probably formed from all the model substances; examples of a typical pyrogram profile at $700{ }^{\circ} \mathrm{C}$ and $20 \mathrm{~s}$, for each sample, are presented in Fig. 3, and the main compounds identified are listed in Table 2. Practically, pyrolysis experiments under the same conditions also led to reproducible results with reasonable accuracy. During the pyrolysis, a wide range of components have been detected and the mechanisms of the formation of several major products in this study are considered similar to those reported by Wang et al. [13]. It was assumed that principally, the formation of each compound group occurs via characteristic mechanisms and pathways. In the case of cellulose pyrolysis [15], ring-opening of glucopyranose units takes place to form open-chain structures, followed by dehydration and cyclization to generate 5-(hydroxymethyl)furfural (5-HMF), which further converts through the elimination of the hydroxymethyl group to produce furfural, and LG is produced by the cleavage of the $\beta-(1 \rightarrow$
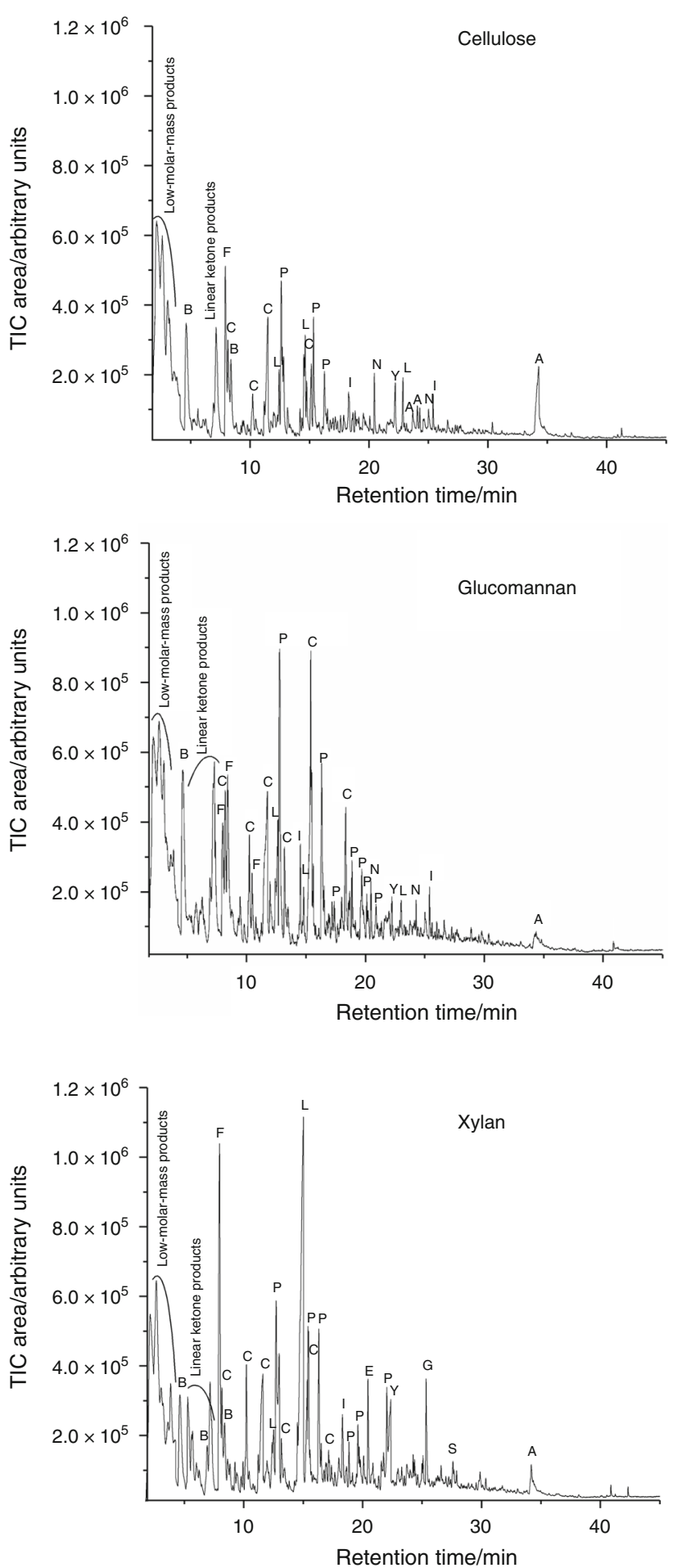

Fig. 3 The main products formed in the pyrolysis experiments ( $700{ }^{\circ} \mathrm{C}$ and $20 \mathrm{~s}$ ) with cellulose, glucomannan, and xylan. Letters indicate compound groups to which identified products belong: A (anhydrosugar derivatives), B (benzene derivatives), C (cyclopentenone derivatives), $\mathrm{E}$ (catechol derivatives), $\mathrm{F}$ (furan derivatives), $\mathrm{G}$ (guaiacol derivatives), I (indene derivatives), L (lactone derivatives), LK (linear ketone derivatives), P (phenol derivatives), S (syringyl derivatives), and $\mathrm{Y}$ (pyrone derivatives) 
Table 2 The main products formed in the pyrolysis experiments with model substances

\begin{tabular}{|c|c|c|c|c|c|}
\hline Product & $\mathrm{RT}^{\mathrm{a}} / \mathrm{min}$ & Cellulose & Glucomannan & Xylan & Group symbol \\
\hline Anhydrosugars & & & & & A \\
\hline 1,4:3,6-Dianhydro- $\alpha$-D-glucopyranose & 24.0 & + & - & - & \\
\hline 2,3-Anhydro-D-mannosae & 24.2 & + & - & - & \\
\hline 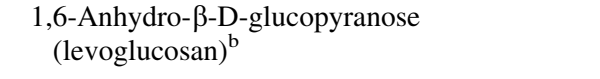 & 34.5 & + & + & + & \\
\hline Benzene derivatives & & & & & B \\
\hline Toluene $^{\mathrm{b}}$ & 4.6 & + & + & + & \\
\hline Cyclopentenone derivatives & & & & & $\mathrm{C}$ \\
\hline Cyclopent-2-en-1-one ${ }^{\mathrm{b}}$ & 8.3 & + & + & + & \\
\hline 2-Methylcyclopent-2-en-1-one ${ }^{\mathrm{b}}$ & 10.3 & - & + & + & \\
\hline 2-Cyclopentene-1,4-dione & 11.2 & + & - & + & \\
\hline 2-Hydroxycyclopent-2-en-1-one & 11.8 & + & + & + & \\
\hline 3-Methylcyclopentane-1,2-dione ${ }^{\mathrm{b}}$ & 15.4 & + & + & + & \\
\hline Catechol derivatives & & & & & $\mathrm{E}$ \\
\hline 2,3-Dihydroxybenzaldehyde & 20.5 & + & + & + & \\
\hline Furan derivatives & & & & & $\mathrm{F}$ \\
\hline Furfural (furan-2-carbaldehyde) ${ }^{\mathrm{b}}$ & 8.0 & + & + & + & \\
\hline 5-Methylfurfural ${ }^{\mathrm{b}}$ & 12.8 & + & + & - & \\
\hline 2,5-Furandicarboxaldehyde ${ }^{\mathrm{b}}$ & 19.1 & + & - & - & \\
\hline 5-(Hydroxymethyl)furfural ${ }^{\mathrm{b}}$ & 24.7 & + & - & - & \\
\hline Guaiacol derivatives & & & & & G \\
\hline 2-Methoxyphenol (guaiacol) ${ }^{\mathrm{b}}$ & 17.2 & - & - & + & \\
\hline 2-Methoxy-4-methylphenol ${ }^{\mathrm{b}}$ & 20.7 & - & - & + & \\
\hline Lactone derivatives & & & & & $\mathrm{L}$ \\
\hline $5 H$-Furan-2-one & 12.7 & + & + & + & \\
\hline 3-Hydroxy-2-penteno-1,5-lactone & 15.0 & + & - & + & \\
\hline 4-Hydroxy-2,5-dimethylfuran-3-one ${ }^{b}$ & 17.8 & + & - & + & \\
\hline 1-Hydroxy-3,6-dioxabicyclo[3.2.1] octan-2-one & 23.2 & + & + & - & \\
\hline Linear ketone derivatives & & & & & LK \\
\hline Methyl acrylate & 5.3 & - & - & + & \\
\hline 1-Hydroxy-2-butanone & 5.7 & + & - & + & \\
\hline 2-Methylbut-2-enal & 6.4 & + & + & - & \\
\hline Valeraldehyde & 7.3 & + & + & - & \\
\hline Phenol derivatives & & & & & $\mathrm{P}$ \\
\hline Phenol $^{\mathrm{b}}$ & 12.9 & + & + & + & \\
\hline 2-Methylphenol ${ }^{\mathrm{b}}$ & 15.5 & + & + & + & \\
\hline 4-Methylphenol ${ }^{\mathrm{b}}$ & 16.4 & + & + & + & \\
\hline 2,4-Dimethylphenol & 18.9 & + & + & + & \\
\hline 4-Ethenylphenol & 22.1 & - & - & + & \\
\hline Syringol derivatives & & & & & $\mathrm{S}$ \\
\hline 2,6-Dimethoxyphenol (syringol) ${ }^{b}$ & 27.6 & - & - & + & \\
\hline Pyrone derivatives & & & & & $\mathrm{Y}$ \\
\hline Pyran-2-one & 14.5 & + & - & - & \\
\hline 3-Hydroxy-2-methylpyran-4-one ${ }^{b}$ & 19.3 & + & - & - & \\
\hline Dihydro-6-methyl-2H-pyran-3(4H)-one & 22.4 & + & + & + & \\
\hline
\end{tabular}

+ Indicates the presence of this compound

${ }^{\mathrm{a}} \mathrm{RT}$ refers to retention time

${ }^{\mathrm{b}}$ Confirmed by pure standards 


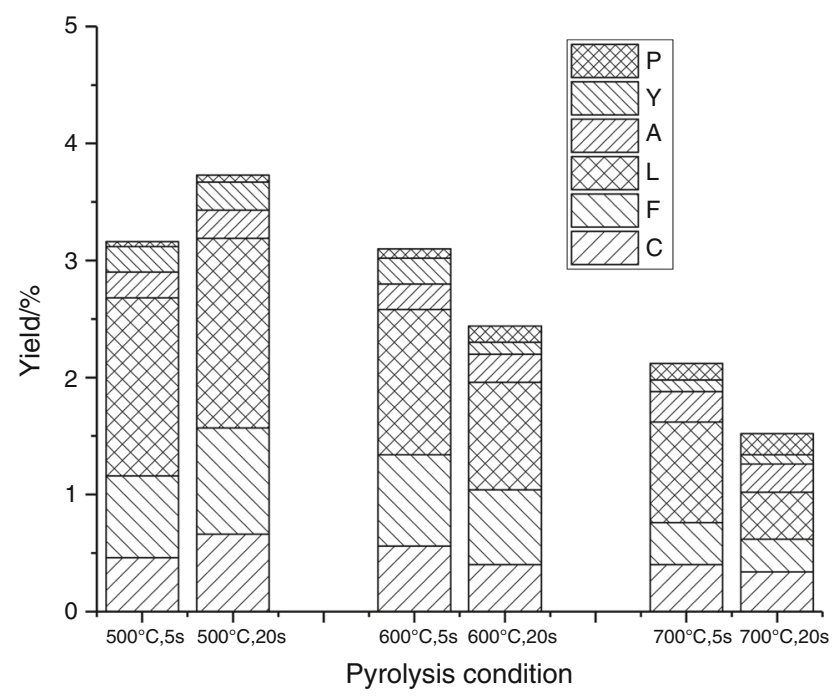

Fig. 4 Effects of pyrolysis temperature and residence time on yields of main product groups from cellulose. For the letter symbols, see Fig. 3

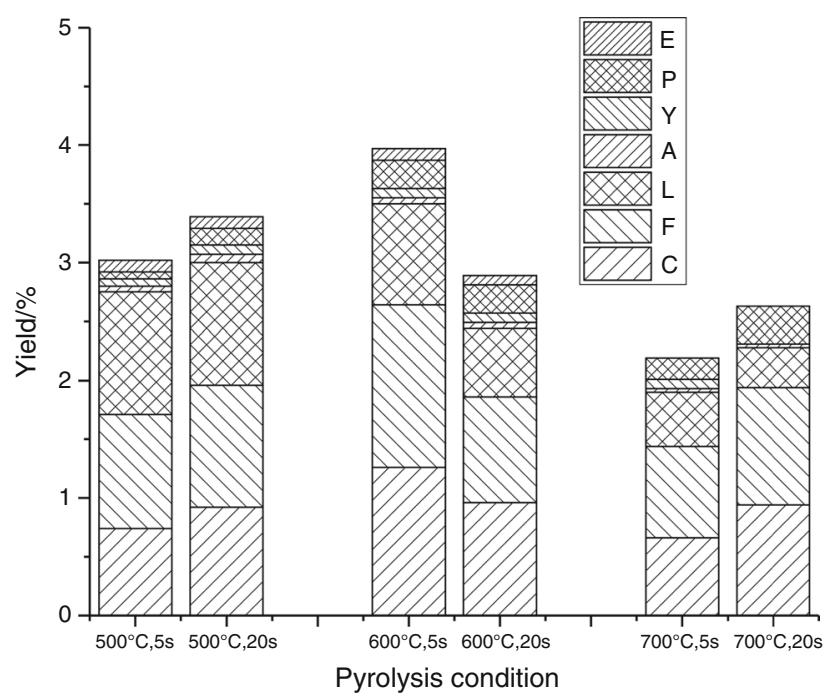

Fig. 5 Effects of pyrolysis temperature and residence time on yields of main product groups from glucomannan. For the letter symbols, see Fig. 3

4)-glycosidic linkage in the cellulose macromolecules, followed by an intramolecular rearrangement. In the case of xylan pyrolysis Shen et al. [36] and Patwardhan et al. [51] have reported that the depolymerization and ring scission of xylan form ring-opened intermediates, which further produce linear ketone products, such as hydroxyacetone (via carbon chain fracture), furfural and lactones (by cyclization), and alicyclic ketones, such as cyclopentenones through the combination of $\mathrm{C}=\mathrm{C}$ bonds. The degradation of glycosidic linkages between monomer units of glucomannan results in anhydrosugars and more stable furan rings (such as 5-HMF, 5-MF, and furfural) $[14,53]$.

Most of these pyrolysis products have been detected earlier in related studies after pyrolysis of polysaccharidescontaining samples or polysaccharides, although in different proportions [4-6, 14-17, 23, 29, 51, 56-60]. In our previous pyrolysis studies with birch wood [4] and spruce wood [5] as well as okra and miscanthus [6], there were several pyrolysis products, such as guaiacol, syringyl, naphthalene, and fatty acid derivatives, that originated from lignin and extractives. However, in this back up study, guaiacol and syringyl derivatives were detected only for xylan, indicating that the xylan preparation used contained some minor guaiacyl-syringyl-type lignin impurities. As a typical trend, in each case, the yield of GCdetectable pyrolysis products decreased steadily toward harsher pyrolysis conditions enhancing the formation of char and volatiles. Hence, the pyrolysis temperature should be shortened to maximize the yield of pyrolysis products (Figs. 4-6). All the compound groups with different relative formation rates were detected within the temperature range studied $\left(500{ }^{\circ} \mathrm{C}, 600{ }^{\circ} \mathrm{C}\right.$, and $700{ }^{\circ} \mathrm{C}$ ), except anhydrosugar derivatives (mainly LG and levoglucosanone), which were prominently obtained only from cellulose.

Figure 7 shows the formation examples of the selected main pyrolysis products from model substances and their formation decreased at the longer holding time (20 s) and the higher reaction temperature $\left(700^{\circ} \mathrm{C}\right)$. It could be noted that, for example, 3-hydroxy-2-penteno-1,5-lactone (lactone) was primarily formed from xylan (also partly from cellulose), $5 H$-furan-2-one (lactone) from glucomannan (also partly from cellulose), 3-methylcyclopentane-1,2dione (cyclopentenone) from glucomannan, furfural (furan) from cellulose and xylan, and 5-HMF (furan) from cellulose. Based on the our previous studies [4-6], of these major pyrolysis products, especially 3-hydroxy-2-penteno1,5-lactone was produced by a factor of three from hardwood [4] than from softwood [5] indicating the presence of a higher portion of xylan in hardwood. However, its yield from hardwood was still less than that from xylan, probably due to an effect of its integration with cellulose and lignin. In the case of $5 \mathrm{H}$-furan-2-one, its formation was less in spruce than pure glucomannan due to their interaction. On the other hand, it decreased in delignified glucomannanpoor softwood samples even by a factor of six, and it could be claimed that this compound originated from glucomannan more readily than from cellulose. A decreasing trend of LG formation in untreated and treated softwood samples manifested that it was formed from both glucomannan and cellulose, but more from cellulose. Also 3-methylcyclopentane-1,2-dione and furfural, are 


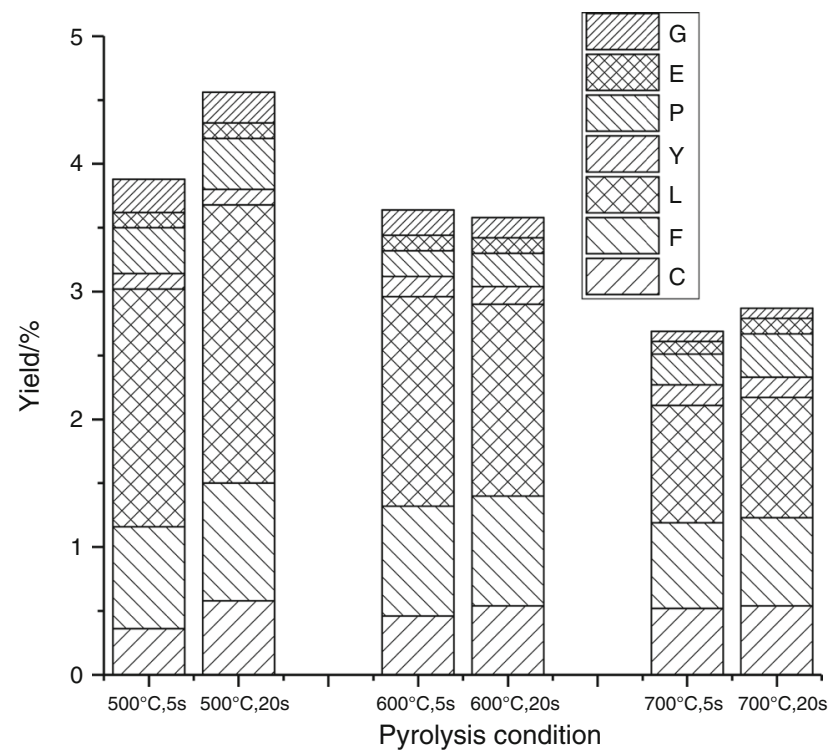

Fig. 6 Effects of pyrolysis temperature and residence time on yields of main product groups from xylan. For the letter symbols, see Fig. 3

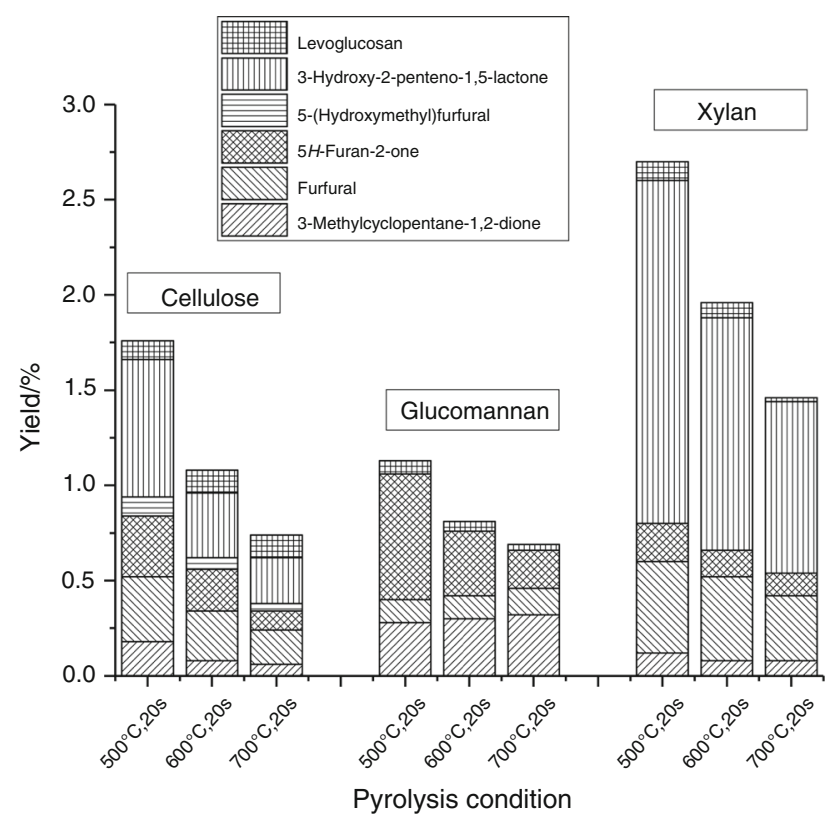

Fig. 7 Effects of temperature and time on yields of some prominent pyrolysis products

prominent products from birch wood and spruce wood as well as non-wood [6].

\section{Formation of pyrolysis products}

It was expected that the total amounts and the relative proportions of varying compounds and compound groups were characteristically dependent on pyrolysis conditions, although the total yield of pyrolysis products that are normally recovered and identified from laboratory-scale pyrolyzers is generally known to be low [61, 62]. A great number of studies have been performed to clarify the reaction networks between the basic structural unit of cellulose, D-glucose, or $\beta$-( $1 \rightarrow 4)$-glycosidic bond-containing low-molar-mass model compounds (e.g., to clarify the role of the dehydration and retroaldol condensation reactions of anhydrosugars and the cleavage of glycosidic bonds) [11, 32, 46]. Typically, the products of cellulose pyrolysis in the classic lumped kinetic models are roughly divided into gases, tar, and char, rather than utilizing the detailed compound distribution. Earlier kinetic studies have been carried out under a variety of pyrolysis conditions, leading to somewhat conflicting data with a wide range of kinetic parameters [37]. Hence, it can be concluded that the kinetics and elementary-reaction chemistry of carbohydrate pyrolysis are still debated [29].

A comprehensive clarification of the myriad pyrolysis reaction routes for cellulose and hemicelluloses was beyond the scope of this study. Instead, the practical aim was to clarify the chemical composition of condensable liquids obtained from these feedstocks at varying temperatures for evaluating the chemical usefulness of the corresponding fractions. Table 3 illustrates the relative formation of the major product groups (lactone, furan, and cyclopentenone derivatives) from cellulose, glucomannan, and xylan under varying pyrolysis conditions, whereas the corresponding formation of the minor product groups (phenolic, pyrone, and anhydrosugar derivatives) is shown in Table 4.

Tables 3 and 4 indicate that no distinct compound group was selectively formed at certain temperatures and the major product groups lactone, furan, and cyclopentenone derivatives accounted for $72-85 \%$ (from cellulose), 86-90\% (from glucomannan), and 76-81\% (from xylan) of the total amount of pyrolysis products determined. In practice, this finding means that if a mixture of cellulose, glucomannan, and xylan with equal proportions would be pyrolyzed at $500{ }^{\circ} \mathrm{C}$, about half of the condensable liquids will consist of lactone derivatives. In the case of cellulose, the proportion of lactone derivatives decreased, and that of anhydrosugar derivatives increased steadily as the temperature increased. For glucomannan and xylan, the proportion of lactone derivatives also decreased and the proportion of cyclopentenone derivatives was slightly depressed toward the maximum temperature. However, for all model substances, no significant changes in the proportion of furan derivatives could be detected. The corresponding major product groups were also prominent ones identified in our earlier pyrolysis experiments, especially at $500{ }^{\circ} \mathrm{C}$, with wood and non-wood feedstocks [4-6] existing together with the lignin-derived significant product groups, guaiacol, and syringyl derivatives. Particularly in the wood 
Table 3 Relative proportions (\%) of major product groups obtained from cellulose, glucomannan, and xylan under varying pyrolysis conditions

\begin{tabular}{llll}
\hline Product group $^{\mathrm{a}}$ & Cellulose & Glucomannan & Xylan \\
\hline $500{ }^{\circ} \mathrm{C}$ & & & \\
$\mathrm{L}$ & $46(1.8)$ & $33(1.1)$ & $48(2.0)$ \\
$\mathrm{F}$ & $23(0.8)$ & $31(1.0)$ & $20(0.8)$ \\
$\mathrm{C}$ & $16(0.5)$ & $26(0.8)$ & $11(0.4)$ \\
$600{ }^{\circ} \mathrm{C}$ & & & \\
$\mathrm{L}$ & $39(1.1)$ & $21(1.5)$ & $43(1.5)$ \\
$\mathrm{F}$ & $26(0.7)$ & $33(1.1)$ & $24(0.8)$ \\
$\mathrm{C}$ & $17(0.5)$ & $32(1.1)$ & $14(0.5)$ \\
$700{ }^{\circ} \mathrm{C}$ & & & \\
$\mathrm{L}$ & $33(0.6)$ & $17(0.4)$ & $33(0.7)$ \\
$\mathrm{F}$ & $18(0.4)$ & $37(0.9)$ & $24(0.7)$ \\
$\mathrm{C}$ & $21(0.4)$ & $33(0.6)$ & $19(0.6)$ \\
\hline
\end{tabular}

The values given in parentheses refer to yields (\% of the initial feedstock dry matter)

Data from Figs. 4-6, calculated average values for heating times of 5 and $20 \mathrm{~s}$

${ }^{\mathrm{a}} \mathrm{L}$ refers to lactone derivatives, $\mathrm{F}$ to furan derivatives, and $\mathrm{C}$ to cyclopentenone derivatives

Table 4 Relative proportions (\%) of minor product groups obtained from cellulose, glucomannan, and xylan under varying pyrolysis conditions

\begin{tabular}{cccc}
\hline Product group $^{\mathrm{a}}$ & Cellulose & Glucomannan & Xylan \\
\hline $500{ }^{\circ} \mathrm{C}$ & & & \\
$\mathrm{P}$ & 1.3 & 3.1 & 9.0 \\
$\mathrm{Y}$ & 6.7 & 2.1 & 2.8 \\
$\mathrm{~A}$ & 6.7 & 1.8 & - \\
$600{ }^{\circ} \mathrm{C}$ & & & \\
$\mathrm{P}$ & 4.0 & 7.1 & 6.3 \\
$\mathrm{Y}$ & 5.6 & 2.4 & 4.2 \\
$\mathrm{~A}$ & 8.5 & 1.5 & - \\
$700{ }^{\circ} \mathrm{C}$ & & & 10 \\
$\mathrm{P}$ & 9.3 & 10 & 5.7 \\
$\mathrm{Y}$ & 5.0 & 2.3 & - \\
$\mathrm{A}$ & 14 & 1.2 & \\
\hline
\end{tabular}

Data from Figs. 4-6, calculated average values for heating times of 5 and $20 \mathrm{~s}$

${ }^{\mathrm{a}} \mathrm{P}$ refers to phenolic derivatives, $\mathrm{Y}$ to pyrone derivatives, and $\mathrm{A}$ to anhydrosugar derivatives

pyrolysis cases, estimated in view of the present results, approximate calculations suggested that the proportions of these compound groups were almost equal to the expected ones.

\section{Conclusions}

Pyrolysis-based technologies can be described as direct thermochemical conversion methods of lignocellulosic biomass carried out in the complete or near complete absence of an oxidizing agent (air or oxygen) typically at 500-700 ${ }^{\circ} \mathrm{C}$ to provide complex fractions of gases, condensable liquids, and char. In many biorefinery concepts, pyrolysis has been applied to prepare fuels and platform chemicals. The pyrolytic degradation of biomass is dominated by the behavior of its structural components, carbohydrates (cellulose and hemicelluloses, such as glucomannan and xylan) and lignin.

In this study, the analytical pyrolysis of cellulose, glucomannan, and xylan was carried out at 500,600, and $700{ }^{\circ} \mathrm{C}$. In each case, the condensable liquids formed were analyzed in detail and classified into several characteristic compound groups. The results revealed that despite some general formation trends, due to many parallel reaction paths, no compound group was selectively formed at certain temperatures, and the major product groups lactone (the most prominent fraction), furan, and cyclopentenone derivatives accounted for $72-85 \%$ (from cellulose), 86-90\% (from glucomannan), and 76-81\% (from xylan) of the total amount of pyrolysis products determined. This study also confirmed by thermogravimetric analyses that within the temperature range studied, cellulose was thermally more stable than the heterogeneous hemicelluloses. All these findings supported those from versatile earlier research and facilitated the creation of a more coherent picture of this complicated area. These kinds of data are of practical importance with respect to efforts to develop new biorefinery possibilities for renewable resources.

Acknowledgements Open access funding provided by University of Jyväskylä (JYU). Financial support from the Academy of Finland, within the framework of the project IMUSTBC (Maryam Ghalibaf) is gratefully acknowledged.

Open Access This article is distributed under the terms of the Creative Commons Attribution 4.0 International License (http://creative commons.org/licenses/by/4.0/), which permits unrestricted use, distribution, and reproduction in any medium, provided you give appropriate credit to the original author(s) and the source, provide a link to the Creative Commons license, and indicate if changes were made.

\section{References}

1. Alén R. Principles of biorefining. In: Alén R, editor. Biorefining of forest resources. Helsinki, Finalnd: Paper Engineers' Association; 2011. p. 55-114.

2. Alén R. Pulp mills and wood-based biorefiners. In: Pandey A, Höfer R, Taherzadeh M, Nampoothiri KM, Larroche C, editors. 
Industrial biorefineries and white biotechnology. Amsterdam, The Netherlands: Elsevier; 2015. p. 91-126.

3. Lehto J. Advanced biorefinery concepts integrated to chemical pulping. Doctoral thesis. University of Jyväskylä, Finland; 2015.

4. Ghalibaf M, Lehto J, Alén R. Fast pyrolysis of hot-water-extracted and delignified silver birch (Betula pendula) sawdust by Py-GC/MS. J Anal Appl Pyrolysis. 2017;127C:17-22.

5. Ghalibaf M, Lehto J, Alén R. Fast pyrolysis of hot-water-extracted and delignified Norway spruce (Picea abies) sawdust by Py-GC/MS. Wood Sci Technol. 2018. https://doi.org/10.1007/ s00226-018-1064-4.

6. Ghalibaf M, Ullah S, Alén R. Fast pyrolysis of hot-water-extracted and soda-AQ-delignified okra (Abelmoschus esculentus) and miscanthus (Miscanthus x giganteous) stalks by Py-GC/MS. Biomass Bioenergy. 2018;118:172-9.

7. Nguyen T, Zavarin E, Barrall EM. Thermal analysis of lignocellulosic materials. Part I. Unmodified materials. J Macromol Sci Part C. 1981;20:1-65.

8. Banyasz JL, Li S, Lyons-Hart J, Shafer KH. Gas evolution and the mechanism of cellulose pyrolysis. Fuel. 2001;80:1757-63.

9. Qu T, Guo W, Shen L, Xiao J, Zhao K. Experimental study of biomass pyrolysis based on three major components: hemicellulose, cellulose, and lignin. Ind Eng Chem Res. 2011;50:10424-33.

10. Van de Velden M, Baeyens J, Brems A, Janssens B, Dewil R. Fundamentals, kinetics and endothermicity of the biomass pyrolysis reaction. Renew Energy. 2010;35:232-42.

11. Wang S, Dai G, Yang H, Luo Z. Lignocellulosic biomass pyrolysis mechanism: a state-of-the-art review. Prog Energy Combust Sci. 2017;62:33-86.

12. Meier D, Faix O. State of the art of applied fast pyrolysis of lignocellulosic materials-a review. Bioresour Technol. 1999;68:71-7.

13. Wang S, Luo Z. Pyrolysis of biomass. Berlin: Walter de Gruyter $\mathrm{GmbH} ; 2017$.

14. Branca C, Di Blasi C, Mango C, Hrablay I. Products and kinetics of glucomannan pyrolysis. Ind Eng Chem Res. 2013;52:5030-9.

15. Lu Q, Yang XC, Dong CQ, Zhang ZF, Zhang XM, Zhu XF. Influence of pyrolysis temperature and time on the cellulose fast pyrolysis products: analytical Py-GC/MS study. J Anal Appl Pyrolysis. 2011;92:430-8.

16. Wang S, Guo X, Liang T, Zhou Y, Luo Z. Mechanism research on cellulose pyrolysis by Py-GC/MS and subsequent density functional theory studies. Bioresour Technol. 2012;104:722-8.

17. Wang S, Liang T, Ru B, Guo X. Mechanism of xylan pyrolysis by Py-GC/MS. Chem Res Chin Univ. 2013;29:782-7.

18. Chen WH, Kuo PC. Isothermal torrefaction kinetics of hemicellulose, cellulose, lignin and xylan using thermogravimetric analysis. Energy. 2011;36:6451-60.

19. Alén R, Rytkönen S, McKeough P. Thermogravimetric behavior of black liquors and their organic constituents. J Anal Appl Pyrolysis. 1995;31:1-13.

20. Elder T. Pyrolysis of wood. In: Hon DN-S, Shiraishi N, editors. Wood and cellulose chemistry. New York: Marcel Dekker; 1991. p. 665-92.

21. Stefanidis SD, Kalogiannis KG, Iliopoulou EF, Michailof CM, Pilavachi PA, Lappas AA. A study of lignocellulosic biomass pyrolysis via the pyrolysis of cellulose, hemicellulose and lignin. J Anal Appl Pyrolysis. 2014;105:143-50.

22. Alén R. Cellulose derivatives. In: Alén R, editor. Biorefining of forest resources. Helsinki: Paper Engineers' Association; 2011. p. $305-54$.

23. Alén R, Kuoppala E, Oesch P. Formation of the main degradation compound groups from wood and its components during pyrolysis. J Anal Appl Pyrolysis. 1996;36:137-48.
24. Piskorz J, Radlein D, Scott DS. On the mechanism of the rapid pyrolysis of cellulose. J Anal Appl Pyrolysis. 1986;9:121-37.

25. Scott DS, Piskorz J, Bergougnou MA, Graham R, Overend RP. The role of temperature in the fast pyrolysis of cellulose and wood. Ind Eng Chem Res. 1988;27:8-15.

26. Radlein D, Piskorz J, Scott DS. Fast pyrolysis of natural polysaccharides as a potential industrial process. J Anal Appl Pyrolysis. 1991;19:41-63.

27. Mamleev V, Bourbigot S, Yvon J. Kinetic analysis of the thermal decomposition of cellulose: the main step of mass loss. J Anal Appl Pyrolysis. 2007;80:151-65.

28. Lanza R, Dalle Nogare D, Canu P. Gas phase chemistry in cellulose fast pyrolysis. Ind Eng Chem Res. 2009;48:1391-9.

29. Lin YC, Cho J, Tompsett GA, Westmoreland PR, Huber GW. Kinetics and mechanism of cellulose pyrolysis. J Phys Chem C. 2009;113:20097-107.

30. Shen $\mathrm{D}, \mathrm{Gu} \mathrm{S}$. The mechanism for thermal decomposition of cellulose and its main products. Bioresour Technol. 2009;100:6496-504.

31. Lédé J. Cellulose pyrolysis kinetics: an historical review on the existence and role of intermediate active cellulose. J Anal Appl Pyrolysis. 2012;94:17-32.

32. Collard FX, Blin J. A review on pyrolysis of biomass constituents: Mechanisms and composition of the products obtained from the conversion of cellulose, hemicelluloses and lignin. Renew Sustain Energy Rev. 2014;38:594-608.

33. Alén R. Structure and chemical composition of biomass feedstocks. In: Alén R, editor. Biorefining of forest resources. Helsinki: Paper Engineers' Association; 2011. p. 17-54.

34. Zhou X, Li W, Mabon R, Broadbelt LJ. A Critical review on hemicellulose pyrolysis. Energy Technol. 2017;5:52-79.

35. Shafizadeh F, McGinnis GD, Philpot CW. Thermal degradation of xylan and related model compounds. Carbohydr Res. 1972;25:23-33.

36. Shen D, Gu S, Bridgwater AV. Study on the pyrolytic behaviour of xylan-based hemicellulose using TG-FTIR and Py-GC-FTIR. J Anal Appl Pyrolysis. 2010;87:199-206.

37. Balat M. Mechanisms of thermochemical biomass conversion processes. Part 1: reactions of pyrolysis. Energ Sources Part A Recovery Util Environ Eff. 2008;30:620-35.

38. Di Blasi C, Lanzetta M. Intrinsic kinetics of isothermal xylan degradation in inert atmosphere. J Anal Appl Pyrolysis. 1997;40-41:287-303.

39. Tian X, Fang Z, Smith RL, Wu Z, Liu M. Properties, chemical characteristics and application of lignin and its derivatives. In: Fang Z, Smith RL, editors. Production of biofuels and chemicals from lignin. Singapore: Springer Science + Business Media Singapore; 2016. p. 3-33.

40. Dhyani V, Bhaskar T. A comprehensive review on the pyrolysis of lignocellulosic biomass. Renew Energy. 2017;245:1-22.

41. Bridgwater AV, Meier D, Radlein D. An overview of fast pyrolysis of biomass. Org Geochem J. 1999;30:1479-93.

42. Yang H, Yan R, Chen H, Lee DH, Zheng C. Characteristics of hemicellulose, cellulose and lignin pyrolysis. Fuel. 2007;86:1781-8.

43. Bridgwater AV. Review of fast pyrolysis of biomass and product upgrading. Biomass Bioenerg. 2012;38:68-94.

44. Várhegyi G, Antal MJ, Jakab E, Szabó P. Kinetic modeling of biomass pyrolysis. J Anal Appl Pyrolysis. 1997;42:73-87.

45. Faix O, Fortmann I, Bremer J, Meier D. Thermal degradation products of wood: gas chromatographic separation and mass spectrometric characterization of polysaccharide derived products. Eur J Wood Wood Prod. 1991;49:213-9.

46. White JE, Catallo WJ, Legendre BL. Biomass pyrolysis kinetics: a comparative critical review with relevant agricultural residue case studies. J Anal Appl Pyrolysis. 2011;91:1-33. 
47. Williams PT, Besler S. Thermogravimetric analysis of components of biomass. In: Bridgwater AV, editor. Advances in thermochemical biomass conversion, Vol 2, Pyrolysis. Dordrecht: Springer; 1993. p. 771-83.

48. Werner K, Pommer L, Broström M. Thermal decomposition of hemicelluloses. J Anal Appl Pyrolysis. 2014;110:130-7.

49. Parker WJ, Levan SL. kinetic properties of the components of Douglas-fir and the heat of combustion of their volatile pyrolysis products. Wood Fiber Sci. 1989;21:289-305.

50. Wang S, Lin H, Ru B, Dai G, Wang X, Xiao G, et al. Kinetic modeling of biomass components pyrolysis using a sequential and coupling method. Fuel. 2016;185:763-71.

51. Patwardhan PR, Brown RC, Shanks BH. Product distribution from the fast pyrolysis of hemicellulose. Chem Sustain energy Mater. 2011;4:636-43.

52. Doddapaneni TRKC, Konttinen J, Hukka TI, Moilanen A. Influence of torrefaction pretreatment on the pyrolysis of Eucalyptus clone: a study on kinetics, reaction mechanism and heat flow. Ind Crops Prod. 2016;92:244-54.

53. Moriana R, Zhang Y, Mischnick P, Li J, Ek M. Thermal degradation behavior and kinetic analysis of spruce glucomannan and its methylated derivatives. Carbohydr Polym. 2014;106:60-70.

54. Jin W, Singh K, Zondlo J. Pyrolysis kinetics of physical components of wood and wood-polymers using isoconversion method. Agriculture. 2013;3:12-32.

55. Janković B, Adnadević B, Jovanović J. Application of modelfitting and model-free kinetics to the study of non-isothermal dehydration of equilibrium swollen poly (acrylic acid) hydrogel: thermogravimetric analysis. Thermochim Acta. 2007;452:106-15.

56. Evans RJ, Milne TA. Molecular characterization of pyrolysis of biomass. 1 fundamentals. Energy Fuels. 1987;1:123-38.

57. Räisänen U, Pitkänen I, Halttunen H, Hurtta M. Formation of the main degradation compounds from arabinose, xylose, mannose and arabinitol during pyrolysis. $\mathrm{J}$ Therm Anal Calorim. 2003;72:481-8.

58. Nowakowski DJ, Jones JM. Uncatalysed and potassium-catalysed pyrolysis of the cell-wall constituents of biomass and their model compounds. J Anal Appl Pyrolysis. 2008;83:12-25.

59. Patwardhan PR, Dalluge DL, Shanks BH, Brown RC. Distinguishing primary and secondary reactions of cellulose pyrolysis. Bioresour Technol. 2011;102:5265-9.

60. Liaw SS, Haber Perez V, Zhou S, Rodriguez-Justo O, GarciaPerez M. Py-GC/MS studies and principal component analysis to evaluate the impact of feedstock and temperature on the distribution of products during fast pyrolysis. J Anal Appl Pyrolysis. 2014;109:140-51.

61. Custodis V, Hemberger P, Ma Z, van Bokhoven J. Mechanism of pyrolysis of lignin: studing model compounds. J Phys Chem B. 2014;118:8524-31.

62. Lappi H. Production of Hydrocarbon-rich Biofuels from Extractives-derived Materials. Doctoral thesis. University of Jyväskylä, Finland; 2012. 